
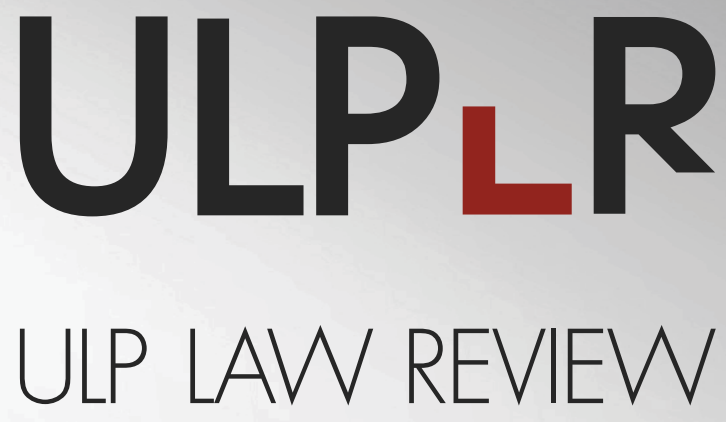

REVISTA DE DIREITO DA ULP

SPECIAL ISSUE 01 I 2022

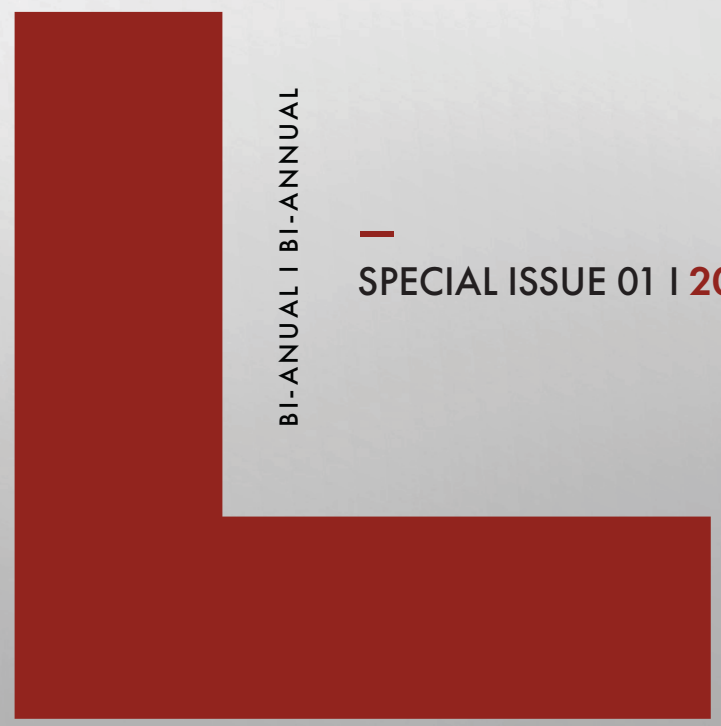

C E A D

FRANCISCO

S U Á R E Z

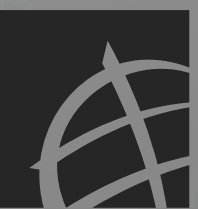

U N I V E R S I D A D E

LUSÓFONA

$\begin{array}{lllllll}D & O & P & O & R & T & O\end{array}$

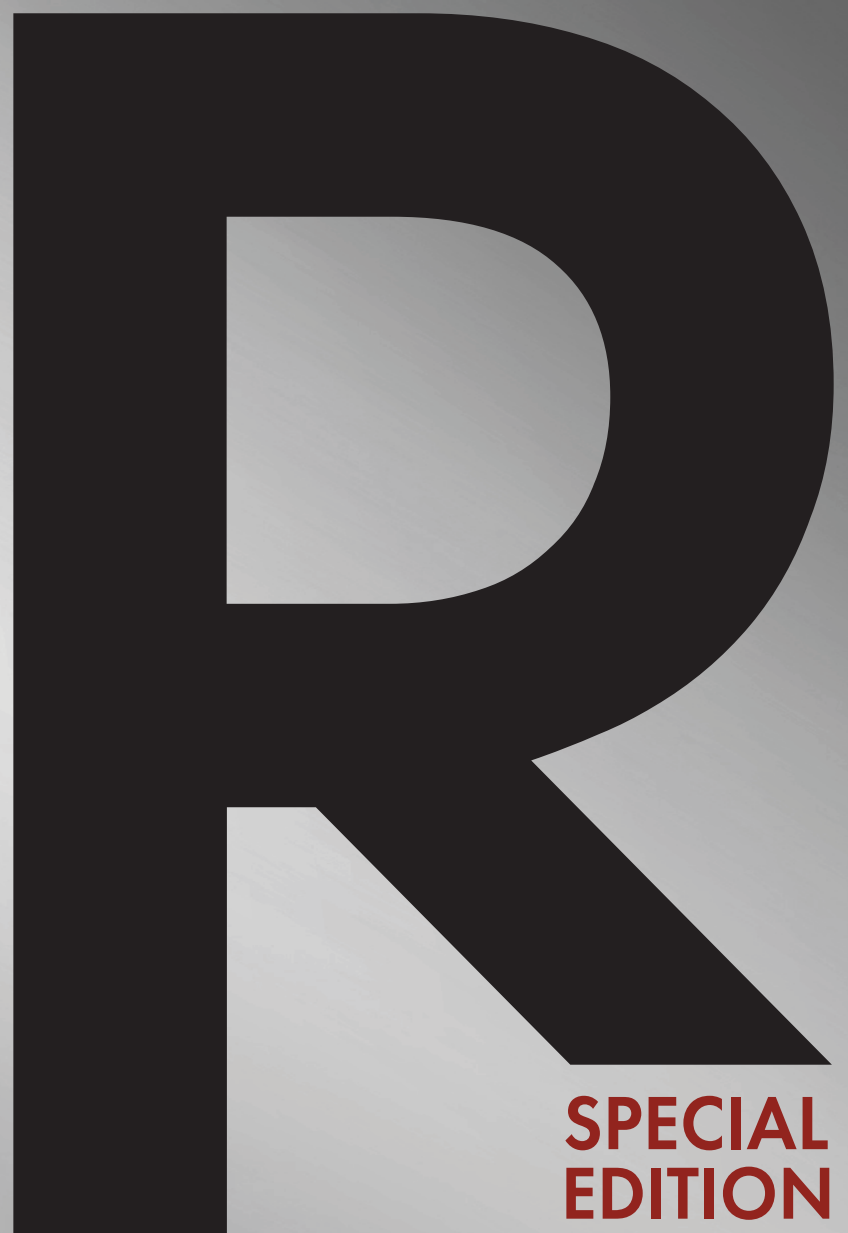

\section{RESEARCH OUTPUTS}

A EMPRESA COMO OBJETO DE INVESTIGAÇÃO POLICÊNTRICA: À LUZ DOS DIREITOS DO AMBIENTE, DA CONCORRÊNCIA, REGULAC̣ÃO, EUROPEU, FISCAL E SANCIONATÓRIO

PAGE 4

\section{ARTICLES}

LÍGIA CARVALHO ABREU - ACORDOS AMBIENTAIS ENTRE EMPRESAS, RESPONSABILIDADE SOCIAL CORPORATIVA E CONCORRÊNCIA

PAGE 6 


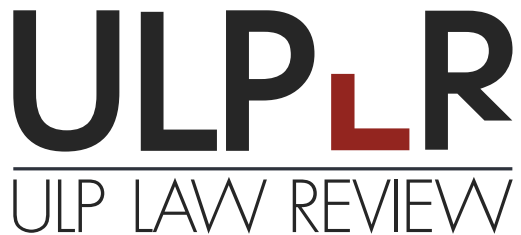

REVISTA DE DIREITO DA ULP

\section{I R E C Ã O}

Inês Fernandes Godinho

Nuno Castro Marques

Fábio Veiga

\section{CONSELHO E DITORIAL}

Fábio Davila (Brasil)

Felix Steffek (R.U.)

Fernando Carbajo Cascón (Espanha) Joachim Renzikowski (Alemanha) João Pateira Ferreira (Portugal)

João Sousa Assis - (Portugal)

José Manuel Aroso Linhares (Portugal)

Kanpirom Kamalarajun (Tailândia)

Laura Mayer Lux (Chile)

Manuel Cabugueira (Portugal)

Maria Natália Gonçalves (Portugal)

Mateusz Klinowski (Polónia)

Nuria Pastor (Espanha)

Paulo Sousa Pinheiro (Portugal)

Sérgio Seminara (Italia)

Urs Kindhäuser (Alemanha)

\section{CONSELHO DE REDAC̣̃̃o}

António Cândido de Oliveira

Rui de Albuquerque

Alexandra Vilela

Maria do Rosário Anjos
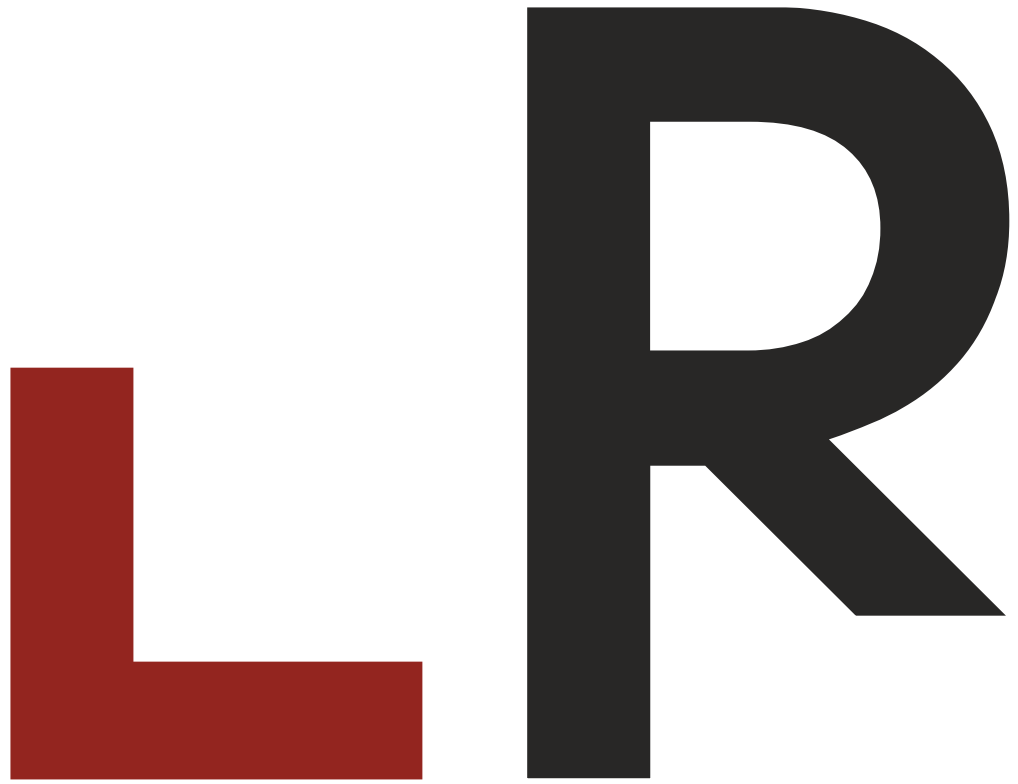

Registo ERC $n .^{\circ} 127458$

Periodicidade: semestral

Proprietário: Cofac-Cooperativa de Formação e Animação Cultural, crl

NIPC: 501679529

Sede: Av. ${ }^{\circ}$ do Campo Grande, 376, 1700-097 Lisboa

Redação: Rua Augusto Rosa, 24, 4000-098 Porto

Estatuto Editorial disponivel em:

hitps://revistas.ulusofona.pt/index.php/rfdulp/about 


\section{CONTENTS/ÍNDICE}

Editorial

Lígia Carvalho Abreu

Acordos ambientais entre empresas, responsabilidade social corporativa e concorrência

6

\section{Nogueira Serens}

"Empresa Locais" e "Grupos de Sociedades": uma comparação

\section{Maria de Fátima Cabrita Mendes}

Os desafios suscitados ao Direito da concorrência da União Europeia pelas grandes empresas

tecnológicas, em especial os casos da apple e da amazon

\section{Nuno Castro Marques}

Os Fundamentos políticos da concorrência: alinhando a defesa da concorrência com a constituição económica e o modelo económico-social português

\section{Domingos Pereira de Sousa}

As Tributações autónomas e a dupla tributação das empresas.

Breve reflexão sobre as incoerências do sistema fiscal português

\section{António Gameiro}

A Soberania e a concorrência fiscal prejudicial na União Europeia

70

\section{Maria do Rosário Anjos}

Concorrência fiscal, competitividade e coesão social na União Europeia

\section{Alexandra Vilela}

Primeira reflexão sobre o novel Regime Jurídico das contra-ordenações económicas 


\section{LINHA DE INVESTIGAC̣ÃO DIREITO ALÉM-FRONTEIRAS}

A Empresa como objeto de investigação policêntrica: à luz dos direitos do ambiente, da concorrência, regulação, europeu, fiscal e sancionatório

\section{Research Output}




\section{EDITORIAL}

A Revista de Direito da ULP/ULP Law Review, sendo uma revista académica que ambiciona contribuir para o avanço da ciência jurídica e enquanto publicação do Centro de Estudos Avançados em Direito Francisco Suárez ICEAD Francisco Suárez), procura, através deste número especial, conjugar os objectivos da Revista e do Centro, publicando um número especial dedicado a um projecto de investigação sobre a "Empresa como objeto de investigação policêntrica", realizado pelos investigadores do CEAD Francisco Suárez integrados na Linha Direito Além-Fronteiras.

Dá-se assim, à estampa um número especial que, tendo como editor o Coordenador da Linha Direito Além-Fronteiras, dá a conhecer à comunidade jurídica os resultados da investigação realizada sob o tema agregador do projecto

Espera-se, deste modo, que a Revista de Direito da ULP/ULP Law Review possa continuar a ser uma publicação de referência.

\section{A Diretora da ULP Law Review}

Inês Fernandes Godinho

\section{APRESENTAC̣ÃO DO RESEARCH OUTPUT}

É com um assumido orgulho que se publica o Research Output 2021 da linha de investigação Direito Além-Fronteiras do CEAD.

O Direito "além-fronteiras" agrega investigações que trabalham o elemento transnacional do direito, mas também as que recolhem os contributos das outras ciências para o Direito, e vice-versa. É, portanto, um campo vastíssimo, que permite acolher a interação do direito com outras ciências, bem como eleger um objeto de estudo e estudá-lo nas suas diferentes possíveis perspetivas ou análises. Foi esta última opção que os Investigadores da linha de investigação Direito Além-Fronteiras tomaram quando, em consenso, decidiram escolher a "Empresa" como tema do primeiro projeto de investigação colaborativa, do qual resultaram os estudos que ora se apresentam. Decidiram, outrossim, que elegeriam anualmente um tema ou "objeto" para colaboração e produção de um Research Output, que poderá apresentar variados formatos. Aqui se apresenta, portanto, o primeiro destes. A Empresa é, então, vista numa primeira dimensão ética e de responsabilidade social, discutindo-se a compatibilidade dos acordos ambientais entre empresas com as regras da concorrência e com a responsabilidade corporativa que se impõe para uma melhor eficácia na resposta aos problemas ambientais globais. Nessa esteira, os próprios limites da qualificação jurídica da Empresa são abordados, em especial face à utilização de instrumentos societários em regime de "grupos de empresas", mas, sobretudo, pela sua utilização para outros escopos por parte de entidades públicas locais que, conclui-se, se afastam da sua essência.

A discussão da posição da Empresa, em especial a dominante, nos mercados digitais, é também aqui trazida, porquanto incontornável no momento presente. E abre-se, também, a discussão sobre os próprios fundamentos do direito da concorrência, quando sujeita a Empresa a um quadro repressivo até agora nunca experienciado.

A Empresa é, depois, abordada enquanto sujeito fiscal, e desde logo sujeito de injustiça tributária por virtude de incongruências e contradições que põem em crise os princípios constitucionais da justiça fiscal e a ética nas relações entre $\circ$ Estado e os contribuintes, mormente no campo dos pagamentos por conta e das tributações autónomas. Mas é também o sujeito que recebe as consequências negativas, no quadro tributário das empresas na União Europeia, da soberania fiscal no atual estado da concorrência fi scal p ejudicial, e ja numa perspetiva estrita da fiscalidade, seja até numa análise dos seus impactos em termos de concorrência, competitividade e coesão económica e social.

Por último, mas last but not least, a perspetiva sancionatória sobre a Empresa, que muito recentemente foi fortemente revista com a aprovação do novel Regime Jurídico das Contra ordenações Económicas.

○ que ora se dá à estampa é o resultado, então, dessa agregação de diferentes abordagens e temas com direta relevância para a Empresa, num conjunto de estudos sob o mote da "Empresa como objeto de investigação policêntrica: à luz dos direitos do ambiente, da concorrência, regulação, europeu, fiscal e sancionatório".

E a todos e a cada um dos Investigadores que integram a linha de investigação Direito Além-Fronteiras, uma palavra de profundo apreço, reconhecimento $e$ gratidão. Torna-se muito menos difícil contribuir para a ciência quando se partilham interesses e motivações com tão sabedores Colegas.

\section{O Coordenador da Linha de Investigação "Direito Além-Fronteiras"}

\section{Nuno Castro Marques}

